\title{
Development of centrifuged cow zygotes cultured in rabbit oviducts
}

\author{
R. J. Wall and H. W. Hawk \\ U.S. Department of Agriculture, Agricultural Research Service, Beltsville Agricultural Research \\ Center, Animal Science Institute, Reproduction Laboratory, Beltsville, Maryland 20705, U.S.A.
}

\begin{abstract}
Summary. Zygotes from superovulated cows were centrifuged and pronuclei were detected by differential interference-contrast microscopy in $73 \%$ of 106 zygotes. Zygotes were then transferred to ligated oviducts of follicular-phase, 1-day pseudopregnant or 7-day pseudopregnant rabbits and recovered 5 days later. Their development did not differ from that of uncentrifuged zygotes transferred to the opposite oviduct: $41 \%$ of the embryos recovered from rabbit oviducts contained 17-32 nuclei and an additional $5 \%$ contained $>32$ nuclei. In another experiment, 399 ova from unmated cows were transferred to rabbit oviducts to determine whether centrifugation induced parthenogenetic development. After 7 days, 257 ova were recovered; $16 \%$ of the recovered ova had developed parthenogenetically and contained $2-30$ nuclei. Neither centrifugation of the ova nor reproductive status of the rabbits influenced the proportion of parthenogenotes found. Parthenogenetic development was also observed in 14 of 71 ova $(20 \%)$ recovered on Day 7 from uninseminated superovulated cows. In an attempt to increase the probability of detecting treatment differences, centrifuged and control cow zygotes were incubated for 7 (rather than 5) days in opposite oviducts of fourteen 1-day pseudopregnant rabbits. Development was unaffected by centrifugation: $61 \%$ of the zygotes recovered had developed beyond the 16-cell stage, with 23,24 and $15 \%$ containing $17-32,33-64$, and $>64$ nuclei, respectively. Taking into account the percentage of zygotes in which pronuclei can be seen, the recovery rate from rabbit oviducts, and the proportion of embryos that develop to the morula stage or beyond, $26 \%$ of the original group of zygotes would be candidates for transfer into recipient cows.
\end{abstract}

Keywords: cattle; pronuclei; centrifugation; parthenogenesis; embryo

\section{Introduction}

A number of embryo manipulation techniques, such as nuclear transfer and DNA microinjection, depend upon visualization of nuclei and pronuclei. However, living zygotes of some species, such as cattle, contain optically dense cytoplasm that obscures nuclear structure. To overcome this problem, pronuclei of cattle zygotes have been stained with fluorescent dyes or the zygotes have been centrifuged to displace the optically dense material within the cytoplasm.

After applying the DNA-specific fluorescent dye 4'-6'-diamidino-2-phenylindole (DAPI) to cow zyogtes, Minhas et al. (1984) were able to view the early stages of fertilization, including pronuclear formation. Subsequently, it was demonstrated that DAPI-treated zygotes can develop into normal calves (Kraemer et al., 1985). Pronuclei have also been revealed in pig and cow zygotes after centrifugation (Wall et al., 1985; Loskutoff et al., 1986). Centrifuged 1and 2-cell pig embryos continue to develop and, if transferred to a recipient gilt, mature to term, resulting in the birth of normal piglets. Preliminary results suggest that this is also true for cow embryos (Loskutoff et al., 1986). 
Several techniques have been used to test the influence of treatments on viability of cattle zygotes. Cow zygotes and cleavage-stage embryos have been evaluated after culture in vitro (Tervit et al., 1972; Camous et al., 1984; Heyman et al., 1987) or after transfer into the oviducts of cows (Rowson et al., 1969), sheep or rabbits (Lawson et al., 1972b; Boland, 1984; Sirard et al., 1985; Eyestone et al., 1985; Lambert et al., 1986; Sirard \& Lambert, 1986). Boland (1984) reviewed the literature regarding optimal conditions for development of cow embryos in rabbit oviducts. However, direct comparisons of the reproductive status of recipient rabbits are limited (Lawson et al., 1972a).

The present study was conducted to determine the proportion of centrifuged cattle zygotes in which pronuclei could be detected (Exp. 1), to evaluate the potential problem of parthenogenetic development of cow ova in rabbit or cow oviducts (Exp. 2), and to assess the influence of centrifugation. on development of cow zygotes for 5 days after their transfer into oviducts of follicular phase, 1-day or 7-day pseudopregnant rabbits (Exp. 3) or for 7 days after their transfer into oviducts of 1-day pseudopregnant rabbits (Exp. 4).

\section{Materials and Methods}

Cows, superovulation and collection of ova/zygotes. The 55 parous Holstein dairy and 30 Angus beef cows were superovulated with a follicle-stimulating hormone (FSH-P: Burns-Biotech, Omaha, NE)/prostaglandin F-2 $\alpha$ (Prostin $\mathrm{F}_{2} \alpha$ : The Upjohn Company, Kalamazoo, MI) regimen as described by Hawk et al. (1988). Cows were slaughtered about $40 \mathrm{~h}$ after the beginning of oestrus, i.e. $\sim 12 \mathrm{~h}$ after the estimated time of ovulation. Reproductive tracts were immediately removed and transported to the laboratory. The oviducts were flushed with $38^{\circ} \mathrm{C}$ phosphate-buffered saline (PBS) as modified by Tervit et al. (1972) and containing $10 \%$ heat-inactivated fetal calf serum (GIBCO, Grand Island, NY). Ova were maintained at $38^{\circ} \mathrm{C}$ in an air atmosphere except as noted below.

Centrifugation of cow zygotes and visualization of pronuclei. Zygotes from 2 or 3 cows were usually pooled and subjected to centrifugation as previously reported (Wall et al., 1985). Briefly, zygotes were transferred to 2-ml microcentrifuge tubes (Sarstedt 72693, Princeton, NJ) containing $38^{\circ} \mathrm{C}$ Hepes-modified Brinster's medium (Hepes-BMOC, as described by Brinster, 1972, with $25 \mathrm{~mm}$-Hepes substituted for $25 \mathrm{~mm}$-bicarbonate). The tubes were sealed and centrifuged for $3 \mathrm{~min}$ at $15600 \mathrm{~g}$ (Eppendorf centrifuge 5412, Fisher Scientific, Richmond, VA).

To visualize pronuclei, centrifuged zygotes were transferred to an oil-covered ( 360 Medical Fluid, 100 centistokes; Dow-Corning, Midland, MI) microdrop of Hepes-BMOC contained on a siliconized depression slide (Fisher Scientific, 12-560A, Richmond, VA). In Exp. 1, the fluorescent DNA dye, Hoechst 33342 (H342, Sigma, St Louis, MO), was added to the Hepes-BMOC ( $10 \mu \mathrm{l}$ of $2 \mathrm{mg} \mathrm{H} 342 / \mathrm{ml} \mathrm{H}_{2} \mathrm{O}$ stock solution added to $1 \mathrm{ml} \mathrm{Hepes-BMOC)}$ so that observations made with interference-contrast optics could be confirmed by fluorescence (Leitz filter cube 'A', excitation $400 \mathrm{~nm}$, BP $340-380 \mathrm{~nm}, \mathrm{LP} 430 \mathrm{~nm}$ ). These observations were performed at room temperature. A total of 239 ova and zygotes was examined. Zygotes in which pronuclei were not apparent or were not distinct were classified as not having visible pronuclei. This criterion was chosen because zygotes with poorly defined pronuclei would not be good candidates for microinjection.

Culture of ova/zygotes in rabbit oviducts. Centrifuged and uncentrifuged zygotes were transferred into opposite ligated oviducts of mature New Zealand White rabbits in a manner similar to that described by Boland (1984). Recipient rabbits were in the follicular phase or 1 day or 7 days pseudopregnant. Pseudopregnancy was induced with 150 i.u. hCG (Lyphomed, Inc., Melrose Park, IL) administered by intravenous injection. Zygotes were introduced into the fimbriated end of the oviduct with a 5- $\mu$ l positive-displacement fixed-volume capillary pipette (Drummond No. 105, Fisher Scientific, Richmond, VA); in some instances, brightly coloured Sephadex-derived density marker beads (Code No. 17-0459-01, DMB-5; Pharmacia Fine Chemicals, Piscataway, NJ) were introduced with each group of zygotes.

To determine whether manipulation of cow ova or their transfer to rabbit oviducts would induce parthenogenetic activation, ova in Exp. 2 were collected from oviducts of uninseminated superovulated cows at necropsy about $40 \mathrm{~h}$ after the beginning of oestrus. Half of the ova were centrifuged, then centrifuged and uncentrifuged ova were transferred to follicular-phase, 1-day pseudopregnant or 7-day pseudopregnant rabbits. After 7 days, the ova were recovered and evaluated.

Ova were also collected non-surgically from uninseminated superovulated cows 7 days after oestrus to ascertain the proportion of unfertilized ova that underwent parthenogenetic development in the cow. The ova were stained and nuclei were counted.

In Exp. 3, centrifuged and uncentrifuged zygotes were randomly assigned to follicular-phase, 1-day or 7-day pseudopregnant rabbits. The embryos were recovered after residing in the ligated rabbit oviducts for 5 days. In Exp. 4 , all centrifuged and uncentrifuged zygotes were transferred to 1-day pseudopregnant rabbits and recovered after 7 days. 
Recovery of cow embryos from rabbit oviducts improved considerably from Exp. $3(58 \%)$ to Exp. 4 (72\%), probably because of a change in the method used to remove the ligature before flushing the oviduct. In Exp. 3, the ligature was removed by sectioning the oviduct on the isthmic side of the ligature. In Exp. 4, the excised oviducts were transilluminated and the brightly coloured beads that were transferred with the zygotes could be seen clustered next to the ligature. The embryos had probably migrated to the same location (Bourdage \& Halbert, 1984). Therefore, the oviducts were sectioned on the utero-tubal side of the ligature. Then the ligature was carefully cut but allowed to remain in place, and the end of the oviduct was gently probed to open the lumen under the ligature. Success of the flushing procedure could be immediately assessed by watching the beads appear in the collection dish. Recovery of beads and embryos was highly correlated $(r=0.94)$ in the 54 oviducts in which the comparison was made.

Evaluation of cow embryo development. Cow zygotes and embryos recovered from rabbit oviducts were stained with $\mathrm{H} 342$ as previously described (Pursel et al., 1985). When oviducts of 1-day pseudopregnant rabbits were flushed, care was taken to distinguish between rabbit and cow ova (Hafez \& Sugie, 1962; Sirard et al., 1985). On rare occasions, differences in thickness of the mucin coat were slight and opacity of the cytoplasm had to be used as the selection criterion.

Statistics. All calculations were performed with the aid of the Statistical Analysis System Version 6 (SAS Institute, Cary, NC). Interference-contrast evaluation of centrifuged zygotes was compared with staining results by $\chi^{2}$ analysis. In experiments in which development of cow zygotes was studied, nuclear counts were converted to cleavage index $\left[=\log _{2}\right.$ (nuclear count)] before the data were analysed. Unfertilized ova were excluded from the analysis. For Exps 2 and 3 , in which ova were transferred into rabbits of three reproductive states, data were subjected to a split-plot analysis. The influence of reproductive status of recipient rabbits was tested using rabbits nested within reproductive status as the error term; the effect of centrifugation and the interaction between reproductive status and centrifugation were tested using the cross product of rabbits and centrifugation nested within reproductive status as the error term. In Exp. 4, in which cow zygotes were transferred only into 1-day pseudopregnant rabbits, the effect of centrifugation on cow egg development was tested using the residual mean square after correcting for variation attributable to rabbits.

\section{Results}

A total of 1660 ova and zygotes was collected from the 85 heifers and cows within 10 min of slaughter. Based on counts of ovulation points, mean \pm s.e.m. egg recovery was $71 \pm 3 \%$ and was unaffected by breed.

\section{Experiment 1: visualization of pronuclei}

After ova and zygotes were centrifuged, the dense material that normally obscures the pronuclei is concentrated on one side of the ova or zygote (the uppermost side during centrifugation). The pronuclei are usually seen, as in pig zygotes (Wall et al., 1985), near the interface of the dense material and the remainder of the cytoplasm.

Pronuclei were believed to have been observed in 79 of the 239 ova and zygotes examined with interference-contrast optics. Staining with $\mathrm{H} 342$ confirmed the presence of pronuclei in 77 out of the 79 zygotes classified as pronuclear. However, 29 of 160 ova (18\%) classified as not having apparent pronuclei by interference-contrast contained two nuclear structures within their cytoplasm after H342 staining.

\section{Experiment 2: parthenogenetic development of cow ova in rabbit oviducts and in vivo}

Parthenogenetic development was initiated in $41(16 \%)$ of 257 ova recovered from rabbit oviducts (Table 1); the proportion differed $(P<0.001)$ for centrifuged ova $(9 \%)$ and ova that were not centrifuged $(26 \%)$. No significant effect of reproductive status of rabbits was detected, although only 1 of six 1-day pseudopregnant rabbits contained parthenogenetically developing cow eggs compared to 5 of 7 follicular-phase and 5 of six 7-day pseudopregnant rabbits that contained parthenogenetic cow ova.

The majority (29) of the activated ova contained between 2 and 4 nuclei: 10 parthenogenotes contained between 5 and 16 nuclei and two contained 30 nuclei. Most parthenogenotes were morphologically abnormal. Although pycnotic nuclei were observed, the majority of the stained 
Table 1. Development of ova collected from uninseminated cows, centrifuged, and cultured for 7 days in opposite oviducts of rabbits of three different reproductive states

\begin{tabular}{|c|c|c|c|c|c|c|}
\hline \multirow[b]{2}{*}{$\begin{array}{l}\text { Treatment } \\
\text { of ova }\end{array}$} & \multirow[b]{2}{*}{$\begin{array}{l}\text { Reproductive } \\
\text { state of } \\
\text { recipient doe }\end{array}$} & \multirow[b]{2}{*}{$\begin{array}{l}\text { No. of } \\
\text { does }\end{array}$} & \multicolumn{3}{|c|}{ Ova recovered from rabbits } & \multirow{2}{*}{$\begin{array}{c}\text { No. of } \\
\text { oviducts } \\
\text { with cleaved } \\
\text { ova }\end{array}$} \\
\hline & & & $\begin{array}{l}\text { Total } \\
\text { no. }\end{array}$ & $\begin{array}{l}\text { No. at } \\
\text { metaphase }\end{array}$ & $\begin{array}{l}\text { No. } \\
\text { cleaved } \\
(\%)\end{array}$ & \\
\hline \multirow[t]{3}{*}{ Centrifuged } & $\begin{array}{l}\text { Follicular } \\
\text { I-day }\end{array}$ & 7 & 65 & 55 & $10(15)$ & 4 \\
\hline & $\begin{array}{l}\text { pseudopregnant } \\
\text { 7-day }\end{array}$ & 6 & 30 & 30 & 0 & 0 \\
\hline & pseudopregnant & 6 & 50 & 47 & $3(6)$ & 3 \\
\hline \multirow[t]{3}{*}{ Uncentrifuged } & $\begin{array}{l}\text { Follicular } \\
\text { 1-day }\end{array}$ & 7 & 45 & 32 & $13(29)$ & 4 \\
\hline & $\begin{array}{c}\text { pseudopregnant } \\
\text { 7-day }\end{array}$ & 6 & 44 & 35 & $9(20)$ & 1 \\
\hline & pseudopregnant & 6 & 23 & 17 & $6(26)$ & 3 \\
\hline
\end{tabular}

nuclei appeared normal. The nuclei of the two most advanced parthenogenotes were strikingly normal in appearance.

The proportion of ova that developed parthenogenetically differed significantly among rabbits $(P=0.005)$ : 8 rabbits had no parthenogenetically developing ova and 11 rabbits contained parthenogenetically developed ova; 3 of these rabbits contained only centrifuged parthenogenotes, 4 contained only control parthenogenotes, and 4 contained centrifuged and control parthenogenotes.

Parthenogenetically activated ova were recovered from 5 of the 12 uninseminated cows that were flushed non-surgically. The mean number of parthenogenotes from the 5 cows was $2 \cdot 8$, range $1-5$ per cow. Of the 71 ova recovered, $14(20 \%)$ had cleaved; 13 ova contained 2 brightly staining nuclei and one other ovum had 3 nuclei. In the remainder of the ova, the DNA appeared as a diffuse cloud typical of degenerating unfertilized ova or as a single small spot of DNA characteristic of metaphase ova.

Experiment 3: culture of cow zygotes in rabbit oviducts for 5 days

After 5 days, 221 ova and embryos were recovered. Recovery rate of embryos $(58 \pm 8 \%$, mean \pm s.e.m. $)$ was not influenced by centrifugation $(P=0.831)$ or reproductive state of the rabbits $(P=0.708)$.

There was a significant interaction between centrifugation and reproductive status of rabbits $(P=0.045)$ on development of the zygotes. Development of cow zygotes, as measured by cleavage index (Table 2), was less advanced for centrifuged zygotes recovered from follicular-phase rabbits and uncentrifuged zygotes collected from 7-day pseudopregnant rabbits than for zygotes recovered from rabbits of other groups. Most of the embryos were at the 5- to 16-cell $(40 \pm 6 \%)$ or 17- to 32 -cell $(41 \pm 6 \%)$ stage with only $5 \pm 2 \%$ of the embryos developed to the $33-$ to 64 -cell stage. Embryo development appeared to be slightly more advanced in 1-day pseudopregnant rabbits than in the others.

\section{Experiment 4: culture of cow zygotes in rabbit oviducts for 7 days}

To determine whether longer culture in rabbit oviducts would increase the sensitivity of the viability test and thus increase the chance of detecting effects of centrifugation, 123 centrifuged and 123 uncentrifuged ova and zygotes were transferred to the opposite oviducts of fourteen 1-day pseudopregnant rabbits. At 7 days after transfer, $72 \pm 6 \%$ of the ova/embryos were recovered. 
Table 2. Development of centrifuged and uncentrifuged cow ova and zygotes cultured for 5 days in opposite oviducts of rabbits of three reproductive states ( 7 recipients in each state)

\begin{tabular}{|c|c|c|c|c|c|c|c|c|}
\hline \multirow[b]{2}{*}{$\begin{array}{l}\text { Egg } \\
\text { treatment }\end{array}$} & \multirow[b]{2}{*}{$\begin{array}{l}\text { Reproductive } \\
\text { state of } \\
\text { recipient doe }\end{array}$} & \multicolumn{2}{|c|}{$\begin{array}{l}\text { Eggs recovered } \\
\text { from rabbits }\end{array}$} & \multicolumn{4}{|c|}{$\%$ Cleaved embryos with: } & \multirow[b]{2}{*}{$\begin{array}{c}\text { Cleavage } \\
\text { index } \dagger\end{array}$} \\
\hline & & $\begin{array}{c}\text { Total } \\
\text { no. }\end{array}$ & $\begin{array}{c}\text { No. } \\
\text { cleaved } \\
(\%)\end{array}$ & $\begin{array}{c}2-4 \\
\text { nuclei }\end{array}$ & $\begin{array}{c}5-16 \\
\text { nuclei }\end{array}$ & $\begin{array}{l}17-32 \\
\text { nuclei }\end{array}$ & $\begin{array}{l}33-64 \\
\text { nuclei }\end{array}$ & \\
\hline \multirow[t]{3}{*}{ Centrifuged } & $\begin{array}{l}\text { Follicular } \\
\text { 1-day }\end{array}$ & 32 & $28 \quad(88)$ & 21 & 25 & 54 & 0 & $3 \cdot 48 \pm 0 \cdot 20^{*}$ \\
\hline & $\begin{array}{c}\text { pseudopregnant } \\
7 \text {-day }\end{array}$ & 33 & $21(64)$ & 10 & 38 & 48 & 5 & $3.96 \pm 0.23$ \\
\hline & pseudopregnant & 47 & $30(64)$ & 7 & 40 & 43 & 10 & $4.02 \pm 0 \cdot 19$ \\
\hline \multirow[t]{3}{*}{ Not centrifuged } & $\begin{array}{c}\text { Follicular } \\
\text { 1-day }\end{array}$ & 27 & $27(100)$ & 7 & 41 & 48 & 4 & $3 \cdot 80 \pm 0 \cdot 20$ \\
\hline & $\begin{array}{c}\text { pseudopregnant } \\
\text { 7-day }\end{array}$ & 42 & $25(60)$ & 4 & 40 & 52 & 4 & $4 \cdot 11 \pm 0 \cdot 21$ \\
\hline & pseudopregnant & 40 & $31 \quad(78)$ & 16 & 68 & 13 & 3 & $3 \cdot 04 \pm 0 \cdot 19$ \\
\hline
\end{tabular}

†Cleavage index $=\log _{2}$ (nuclei), mean \pm s.e.m.

*A significant interaction was detected between zygote treatment and reproductive state of doe $(P=0.045)$.

Table 3. Development of centrifuged and uncentrifuged cow ova and zygotes cultured for 7 days in opposite oviducts of 1-day pseudopregnant rabbits $(\mathrm{N}=14)$

\begin{tabular}{|c|c|c|c|c|c|c|c|c|}
\hline \multirow[b]{2}{*}{$\begin{array}{l}\text { Egg } \\
\text { treatment }\end{array}$} & \multicolumn{2}{|c|}{$\begin{array}{l}\text { Eggs recovered } \\
\text { from rabbits }\end{array}$} & \multicolumn{5}{|c|}{$\%$ Cleaved embryos with: } & \multirow[b]{2}{*}{$\begin{array}{l}\text { Cleavage } \\
\text { index }{ }^{\dagger}\end{array}$} \\
\hline & $\begin{array}{c}\text { Total } \\
\text { no. }\end{array}$ & $\begin{array}{l}\text { No. } \\
\text { cleaved } \\
(\%)\end{array}$ & $\begin{array}{c}2-4 \\
\text { nuclei }\end{array}$ & $\begin{array}{c}5-16 \\
\text { nuclei }\end{array}$ & $\begin{array}{l}17-32 \\
\text { nuclei }\end{array}$ & $\begin{array}{l}33-64 \\
\text { nuclei }\end{array}$ & $\begin{array}{c}>64 \\
\text { nuclei }\end{array}$ & \\
\hline Centrifuged & 84 & $40(48)$ & 15 & 20 & 23 & 33 & 10 & $4.22 \pm 0.23$ \\
\hline Not centrifuged & 71 & $40(56)$ & 10 & 33 & 23 & 15 & 20 & $4 \cdot 20 \pm 0.23$ \\
\hline
\end{tabular}

$\left\lceil\right.$ Cleavage index $=\log _{2}$ (nuclei).

Centrifugation did not significantly $(P=0.256)$ influence development of cow zygotes (Table 3). However, allowing the embryos to reside in rabbit ovidcuts for an additional 2 days increased the proportion of embryos with 33 or more nuclei (compare percentages in Tables 2 and 3): 12 (15\%) of the recovered embryos contained more than 64 nuclei and most were in the expanded blastocyst stage of development.

\section{Discussion}

Pronuclei were observed in $73 \%$ of centrifuged cattle zygotes (pronuclei detected in 77 and missed in 29 zygotes). In sheep, whose eggs do not require centrifugation for pronuclei to be seen (Nancarrow et al., 1984), pronuclei have been detected in $80 \%$ of zygotes (Hammer et al., 1985). Although data of this type are not available for pig zygotes, pronuclei are apparently missed in about $25 \%$ of centrifuged zygotes in that species (V. G. Pursel, personal communication). It is not known why a proportion of the pronuclei cannot be detected with differential interference-contrast optics in these zygotes. In centrifuged cow and pig zygotes, pronuclei may migrate with or be covered by the 
migration of optically dense material in the cytoplasm. The latter explanation is supported by an electron microscope study of ultracentrifuged mouse zygotes that found orientation of the eggs, during centrifugation, to be random (Mulnard \& Puissant, 1984). It is also possible that, in recently fertilized zygotes, in which pronuclei are located near the vitelline membrane, optical contrast is reduced and some of the pronuclei may be overlooked. Although a proportion of observed pronuclei are peripheral, the vast majority are centrally located. Ova that are approaching syngamy, when nuclear envelopes break down, may account for a small proportion of the zygotes in which pronuclei are not observed. However, when stained, the pronuclear material is usually found in distinctly separate locations, not together, as would be the case at the time of syngamy.

Cow zygotes tolerated centrifugation with no detectable loss in viability. However, a higher proportion of centrifuged zygotes that were cultured in rabbit oviducts for 7 days contained 33-64 nuclei and a lower proportion contained more than 64 nuclei when compared to uncentrifuged zygotes (Table 3 ). The same relationship was observed when viability of centrifuged pig zygotes was tested (Wall et al., 1985). Centrifugation resulted in fewer sheep blastocysts (Nancarrow et al., 1984) and fewer mice born (Mulnard \& Puissant, 1984; Nakamura et al., 1986).

Cow zygotes have been successfully cultured in rabbit oviducts by numerous investigators (for review, see Boland, 1984). When the embryos are subsequently transferred to cows, pregnancies result (Lawson et al., 1972b; Sirard et al., 1985). In most studies, cow embryos were recovered from rabbits after 3 or 4 days. Culture periods of 5 and 7 days were used in this study to increase the proportion of recovered embryos that would have developed to blastocysts or expanded blastocysts. Because it was anticipated that a high proportion of the embryos recovered from rabbit oviducts would be morulae or blastocysts, nuclei were counted to avoid the problem of distinguishing between morulae and fragmented ova or embryos with few nuclei. To compare the rate of development of cow embryos in these experiments with previously published morphological classifications, the assumption was made that morulae contain 10-20 cells, blastocysts $21-36$ cells, and expanded blastocysts more than 36 cells. This classification is an approximation because stained blastocysts were seen with as few as 20 nuclei and morulae with more than 40 nuclei. Nevertheless, the stages of development of embryos recovered after 5 days in rabbit oviducts (collected from cows about 1.7 days after the beginning of oestrus) were similar to stages reported for embryos with a chronological age of 6-7 days collected from cows (Shea, 1981; Lindner \& Wright, 1983) and for cow embryos cultured in rabbit oviducts (Boland, 1984). Embryos cultured for 7 days in rabbit oviducts were intermediate in development between embryos recovered from cows 7 and 8 days after oestrus (Shea, 1981; Lindner \& Wright, 1983; Boland, 1984). Even though the development of centrifuged cow zygotes appeared to be slowed by about half of a cleavage division as compared to uncentrifuged embryos, development of the centrifuged embryos fell within normal limits when compared to embryos of the same chronological age collected from cows.

Oviducts of follicular-phase (Lawson et al., 1972a; Boland et al., 1976) and pseudopregnant (Hafez \& Sugie, 1962; Sirard et al., 1985) rabbits have been used as sites for culturing cow embryos with varied degrees of success. The only direct comparison of reproductive status of rabbits on embryo development was performed with a mixture of 2- and 4-cell sheep embryos (Lawson et al., 1972b). Sheep embryos appeared to develop slightly faster in pseudopregnant hosts, but the results were confounded by the proportion of 2- and 4-cell embryos transferred. In the current study, there was a slight but non-significant advantage in development for cow zygotes transferred to 1-day pseudopregnant rabbits (Table 2). Also, when ova collected from cows that were not inseminated were transferred to rabbits of three reproductive states, parthenogenetic development was least apparent in 1-day pseudopregnant rabbits (Table 1). In experiments designed to study early cleavage events, there may be an advantage in using 1-day pseudopregnant rabbits to limit the confounding effect of parthenogenetic development.

Parthenogenetic development of cow ova matured in vitro has ranged between 10 and $16 \%$ (Trounson et al., 1977; Xu et al., 1986). In both studies, cow ova were cultured in rabbit oviducts, but in neither study was it determined whether parthenogenetic activation was a consequence of 
culture in rabbit oviducts. In the present study, $20 \%$ of ova collected from 12 unmated cows 7 days after oestrus showed clear signs of parthenogenetic activation. When ova from unmated cows were transferred to rabbits, the overall rate of parthenogenesis was $16 \%$. These percentages suggest that little if any of the parthenogenetic development observed in previous studies was caused by in-vitro maturation of oocytes. The fact that no parthenogenote recovered directly from cows had more than 3 nuclei compared with as many as 30 nuclei in a few parthenogenotes cultured in rabbit oviducts suggests that rabbit oviducts provided a more hospitable environment for developing parthenogenotes. Unexpectedly, a lower percentage of parthenogenotes were observed in ova that were centrifuged than in the uncentrifuged group. The reason for this difference is unknown. Centrifugation stratifies the cytoplasmic contents of ova and therefore may separate some components that normally interact to cause parthenogenesis. Alternatively, parthenogenetically activated ova may be particularly sensitive to mechanical perturbations and become arrested as a result of centrifugation.

Based on the data presented here, centrifugation makes it possible to see pronuclei in $73 \%$ of cattle zygotes. After 7 days of culture in rabbit oviducts, about $70 \%$ of the cow eggs can be recovered, and about $50 \%$ of those eggs would be candidates for non-surgical embryo transfer.

We thank Henry Conley and Mark Spencer for their excellent technical assistance and Linda Neuenhahn for preparation of this manuscript.

\section{References}

Boland, M.P. (1984) Use of the rabbit oviduct as a screening tool for the viability of mammalian eggs. Theriogenology 21, 126-137.

Boland, M.P., Crosby, T.F. \& Gordon, I. (1976) Induction of twin pregnancy in heifers using a simple nonsurgical technique. Proc. 8th Int. Congr. Anim. Reprod. \& A.I., Cracow 3, 241-244.

Bourdage, R.J. \& Halbert, S.A. (1984) Quantification of intraluminal motion of surrogate ova in the rabbit oviductal isthmus. Biol. Reprod. 30, 1124-1129.

Brinster, R.L. (1972) Cultivation of the mammalian embryo. In Growth, Nutrition, and Metabolism of Cells in Culture, vol. II, pp. 251-286. Eds G. Rothblatt \& V. Cristofalo. Academic Press, New York.

Camous, S., Heyman, Y., Meziou, W. \& Menezo, Y. (1984) Cleavage beyond the block stage and survival after transfer of early bovine embryos cultured with trophoblastic vesicles. J. Reprod. Fert. 72, 479 485.

Eyestone, W.H., Northey, D.L. \& Leibfried-Rutledge, M.L. (1985) Culture of 1-cell bovine embryos in the sheep oviduct. Biol. Reprod. 32 (Suppl. 1), 100, Abstr.

Hafez, E.S.E. \& Sugie, T. (1962) Reciprocal transfer of cattle and rabbit embryos. J. Anim. Sci. 21, 30-35.

Hammer, R.E., Pursel, V.G., Rexroad, C.E., Jr, Wall, R.J., Bolt, D.J., Ebert, K.M., Palmiter, R.D. \& Brinster, R.L. (1985) Production of transgenic rabbits, sheep and pigs by microinjection. Nature, Lond. 315, 680-683.

Hawk, H.W., Conley, H.H., Wall, R.J. \& Whitaker, R.O. (1988) Fertilization rates in superovulating cows after deposition of semen on the infundibulum or near the uterotubal junction or after insemination with high numbers of sperm. Theriogenology 29 (In Press).

Heyman, Y., Menezo, Y., Chesne, P., Camous, S. \& Garnier, V. (1987) In vitro cleavage of bovine and ovine early embryos: improved development using coculture with trophoblastic vesicles. Theriogenology 27, 59-68.

Kraemer, D., Minhas, B. \& Capehart, J. (1985) Gene transfer into pronuclei of cattle and sheep zygotes. In Genetic Manipulation of the Early Mammalian Embryo, pp. 221-227. Eds F. Constantini \& R. Jaenisch. Cold Spring Harbor Laboratory, Cold Spring Harbor.

Lambert, R.D., Sirard, M.A., Bernard, C., Beland, R., Rioux, J.E., Leclerc, P., Menard, D.P. \& Bedoya, M. (1986) In vitro fertilization of bovine oocytes matured in vivo and collected at laparoscopy. Theriogenology 25, 117-133.

Lawson, R.A.S., Adams, C.E. \& Rowson, L.E.A. (1972a) The development of sheep eggs in the rabbit oviduct and their viability after re-transfer to ewes. J. Reprod. Fert. 29, 105-116.

Lawson, R.A.S., Rowson, L.E.A. \& Adams, C.E. (1972b) The development of cow eggs in the rabbit oviduct and their viability after re-transfer to heifers. $J$. Reprod. Fert. 28, 313-315.

Lindner, G.M. \& Wright, R.W. (1983) Bovine embryo morphology and evaluation. Theriogenology 20, $407-416$.

Loskutof, N.M., Coren, B.R., Barrios, D.R., Bessoudo, E., Bowen, M.J., Stone, G. \& Kraemer, D.C. (1986) Gene microinjection in bovine embryos facilitated by centrifugation. Theriogenology 25, 168, Abstr.

Minhas, B.S., Capehart, J.S., Bowen, M.J., Womack, J.E., McCrady, J.D., Harms, P.G., Wagner, T.E. \& Kraemer, D.C. (1984) Visualization of pronuclei in living bovine zygotes. Biol. Reprod. 30, 687-691.

Mulnard, J. \& Puissant, F. (1984) Development of mouse embryos after ultracentrifugation at the pronuclei stage. Archs Biol. (Bruxelles) 95, 461-474.

Nakamura, K., Tsunoda, Y., Nagai, T. \& Sugie, T. (1986) 
Effect of centrifugation of mouse eggs on their development in vitro and in vivo. Gamete Res. 15, 83-86.

Nancarrow, C.D., Murray, J.D., Boland, M.P., Hazelton, I.G. \& Sutton, R. (1984) Toward gene transfer into ruminant embryos: effect of centrifugation. Theriogenology 21, 248, Abstr.

Pursel, V.G., Wall, R.J., Rexroad, C.E., Jr, Hammer, R.E. \& Brinster, R.L. (1985) A rapid whole-mount staining procedure for nuclei of mammalian embryos. Theriogenology 24, 687-691.

Rowson, L.E.A., Moor, R.M. \& Lawson, R.A.S. (1969) Fertility following egg transfer in the cow: effect of method, medium and synchronization of oestrus. $J$. Reprod. Fert. 18, 517-523.

Shea, B.F. (1981) Evaluating the bovine embryo. Theriogenology 15, 31-42.

Sirard, M.A. \& Lambert, R.D. (1986) Birth of calves after in vitro fertilization using laparoscopy and rabbit oviduct incubation of zygotes. Vet. Rec. 119, 167-169.

Sirard, M.A., Lambert, R.D., Menard, D.P. \& Bedoya, M. (1985) Pregnancies after in-vitro fertilization of cow follicular oocytes, their incubation in rabbit oviduct and their transfer to the cow uterus. J. Reprod. Fert. 75, 551-556.

Tervit, H.R., Whittingham, D.G. \& Rowson, L.E.A. (1972) Successful culture in vitro of sheep and cattle ova. $J$. Reprod. Fert. 30, 493-497.

Trounson, A.O., Willadsen, S.M. \& Rowson, L.E.A. (1977) Fertilization and development capability of bovine follicular oocytes matured in vitro and in vivo and transferred to the oviducts of rabbits and cows. J. Reprod. Fert. 51, 321-327.

Wall, R.J., Pursel, V.G., Hammer, R.E. \& Brinster, R.L. (1985) Development of porcine ova that were centrifuged to permit visualization of pronuclei and nuclei. Biol. Reprod. 32, 645-651.

Xu, K.P., Greve, T., Smith, S., Liehman, P., Callesen, H. \& Hyttel, P. (1986) Parthenogenetic activation of cattle oocytes matured in vitro and cultured in rabbit oviducts. Theriogenology 25, 218, Abstr.

Received 20 July 1987 